\title{
Labor Market Experiences and Expectancies
}

\author{
Patricia Gurin \\ Department of Psychology \\ Institute for Social Research, University of Michigan
}

Comparisons are made of the labor market experiences of a national sample of employed Black and White men and women. While women had "invested in their human capital" nearly as often as men, they less often had tried job training or job changes, and more often had acquired additional schooling, to improve their market positions. Compared to White men, both groups of women also expressed lower work-related expectancies. Part of the White male expectancy edge can be attributed to differences in past investment strategies. Black and white women who had tried to make work changes did not differ from White men in present expectancies. While the causal relationship between experiences and expectancies needs further examination, especially in longitudinal studies, these results suggest that adult socialization in the labor market, while generally neglected, is a potentially important area of research on women's employment.

Research on women's labor force participation and employment patterns has emphasized women's work motivation, sex-role attitudes, and the early home and school socialization through which these work-related dispositions presumably develop. Far less attention has been given to adult socialization and labor market experiences as influences on women's employment (Gutek \& Nieva, 1978). Moreover, women's career preferences and their motives and values have been stressed more than their expectancies of success (Laws, 1976), although both expectancies and values are viewed as critical to work motivation in the dominant theories in organizational psychology.

The dual emphasis on the value-motive aspect of motivation and on preadult socialization is reasonable because empirical evidence to date generally shows early sex differences in career "preferences." Boys and girls as young as kindergarten also substantially agree that some jobs are appropriate for males and others for females (Shepard \& Hess, 1975; Looft, 1971a, 1971b; Siegel, 1973). Moreover, despite large increases in female employment in recent years, most women still work in traditionally "female" jobs, and research evidence 
continues to show sizable sex differences in academic field and occupational preferences. Siegel (1973) and Looft (1971a, 1971b) both found that two-thirds of the first- and second-grade girls they studied wanted to be teachers or nurses. Women at both high school and college levels also predominantly aspire to jobs held presently by women - teaching, nursing, secretarial and clerical jobs, and social work (Tangri, 1972, Barnett, 1975; Feldman, 1974). Also, since occupational differentiation by sex, through which women and men end up in different jobs, is an important determinant of wage differentials by sex, ${ }^{1}$ women's choices and preferences have understandably received research attention.

Preferences, like behavior, reflect expectancies as well as motives and values. Women may state preferences for lower paying "traditional" jobs because they fear success, do not value achievement (at least in work roles), and/or because they hold low expectancies of getting other jobs. The few studies that have measured expectancies typically show that sex differences in preferences are reduced when men's and women's level of expectancy is equated (Crowley, Levitin, \& Quinn, 1973). Among women who judge their chances for getting "masculine" jobs as optimistically as men, preference is also equivalent. The impact of expectancy is also demonstrated in a study of the value placed on job challenge by men and women. Data from a national sample of working men and women show that when the jobs held by men and women provided them with challenge, they valued challenge equally often as an important element in work. When their current jobs were unchallenging, women valued work challenge less than men (Levitin \& Quinn, personal communication). Data from the same national study make the same argument about men's and women's desires to be promoted. In response to the question about when they would like to take a job at a higher level, more women than men said they never wanted to be promoted. Women also expressed lower expectancies of being given a chance for promotion. However, once expectancy of promotion was controlled, sex differences in desire for promotion disappeared. When women believed they could be promoted, they wanted to be promoted as much as men. Results such as these indicate that women's employment expectancies might prove highly important if investigated as thoroughly as other aspects of their work motivation.

The research reported here explores the expectancy aspect of work motivation with a national sample of employed adults. It focuses on adult socialization in the labor market. Workers' present job-related expectancies are viewed as influenced by past labor market experiences. Two hypotheses are tested. White men, the group that has fared best in the market, were predicted to show both an experience and expectancy advantage relative to women (both Black

\footnotetext{
${ }^{1}$ Studies of sex differentials in wages also generally, however, agree that sex differences remain sizable after occupational characteristics are controlled (Hamilton, 1973; Oaxaca, 1973).
} 
and White) and to Black men. Differences between White men and both groups of women's experiences were then hypothesized as largely accounting for women's reduced expectancies of success. (The expectancy implications of black men's experiences are not reported here.) ${ }^{2}$ This article therefore examines sex differences in work motivation but in aspects only rarely measured in previous work on male and female workers.

\section{METHOD}

\section{Sample}

The sample, individuals interviewed in the 1972 national election study conducted by The Survey Research Center at The Unviersity of Michigan were a representative cross-section of persons 18 years of age or older who were United States citizens living in private households in the coterminous United States. ${ }^{3}$ The personal interviews were carried out at the homes of these individuals both before and after the national election. The overall response rate for the preelection survey was $75.1 \%$. The postelection interviews, which contained the questions on labor market experience and current expectancies, were conducted with 2,191 of the 2,705 individuals who responded to the preelection interview. The overall reinterview rate of $80.9 \%$ was approximately the same for all race and sex groups: $80 \%$ for White men, $81 \%$ for White women, $77 \%$ for Black men, and $83 \%$ for Black women. The analyses reported here include only respondents who were either currently employed or worked at some point in the previous year. This includes 850 White men, 542 White women, 79 Black men, and 100 Black women from the postelection survey.

\section{Measures}

Labor Market Experiences. Respondents were asked about their previous attempts to improve their market situation. These might be viewed, from a human capital perspective, as their investment strategies: "Was there ever a time

\footnotetext{
${ }^{2}$ See Gurin and Morrison (1976) for analyses of the data for Black men.

${ }^{3}$ The 12 largest metropolitan areas of the United States were drawn with certainty. The rest of the country was formed into 62 strata, each of which contained two or more primary sampling units. From each stratum a primary sampling unit (PSU), consisting of a county or a group of counties, was drawn with probability proportional to its 1970 population. Seventy-four PSUs were drawn and the selection procedure within the PSUs yielded a sample of private households. Respondents were selected from households by an objective selection procedure which allowed no substitutions.
} 
when you tried to change what you are doing - for example, entered a training program, went back to school, tried to go into a different type of work - things that would really change what you were doing?" Respondents who had tried something were then asked what they had done. Three dichotomous measures were developed from responses to these questions: (1) tried versus did not try to change, (2) tried work change versus did not, (3) tried educational change versus did not. Work changes included job shifts, job training, promotions. Educational changes included attempts to get more education or training in a formal educational setting. not on the iob.

Two additional questions were also treated as generalized market experience measures, although the questions did not specifically refer to the labor market. One asked whether respondents felt they had had a fair opportunity to make the most of themselves in life or whether they had been held back in some ways; the other asked whether they had been able to satisfy most of their ambitions in life or whether they had had to settle for less than they had hoped for. The reasons given for feeling held back, settling for less than one's ambitions, and for any difficulty they had experienced in their previous "investment" or "change" efforts were coded with the same categories of attributions. One included the number of times across these three questions that the respondent attributed difficulties to market constraints - lack of opportunity, lack of jobs, race or sex discrimination, plant closings, layoffs, etc. The second included the number of times that difficulties were attributed to educational deficiencies lack of education, lack of specific educational credentials or qualifications. People who felt they had had fair opportunity, had satisfied most of their ambitions, or had not experienced any difficulties in carrying out the changes they had attempted were scored as experiencing no market constraints and no educational deficiencies.

Expectancies. A global employment expectancy measure asked: "If you should lose your present job, what would you say were your changes of finding another job that was just as good as your present job in all respects?" Respondents chose among four alternatives (very good, good, not so good, and not good at all). A performance-based expectancy was then measured by asking how much ability respondents thought they had, compared to most other people doing their kind of work. Respondents chose among four alternatives (much more, a little more, about the same, and a little less).

Respondents were also asked four questions that have been used to indicate a sense of personal efficacy in many Survey Research Center studies: "Do you think it is better to plan your life a good way ahead, or would you say life is too much a matter of luck to plan ahead very far?" "When you do make plans ahead, do you usually get to carry out things the way you expected, or do things usually come up to make you change your plans?" "Have you usually felt pretty sure that your life would work out the way you want it to, or have there been times when you haven't been sure about it?" And "Some people feel they can 
run their lives pretty much the way they want; others feel the problems of life are sometimes too big for them. Which one are you most like?" The coefficient alpha of the summary efficacy score is .74. This sense of efficacy is far more generalized than the employment and performance expectancies and also addresses the issue of personal control of outcomes.

\section{Analyses}

Differences between White men's and the other three groups of workers' experiences and expectancies were tested by a series of Scheffé contrasts, which are somewhat more conservative than tests for planned comparisons. However, since differences among the other three groups of workers were also of interest, a post hoc statistic was used for all comparisons. The predicted role of labor market experience in accounting for the White male edge in expectancy was tested through dummy regression analyses. White men were treated as the constant, White women were coded 1 and Black women 0 in the first dummy variable, and Black women were coded 1 and White women 0 in the second dummy variable. Black men were deleted from this analysis, since we were concerned explicitly with the role of experience in the expectancies of women relative to White men. Significant coefficients for the two dummy variables indicate that being a White woman or a Black woman has an effect in expectancies, specifically compared to White men. In the first dummy regression, years of schooling was also entered as a predictor so that the Black woman and White woman effects would represent differences from White men even after adjustment for educational attainments. White men had slightly more schooling than White women and significantly more than Black women. In the second dummy regression, a market experience predictor was added. The major question was whether the White male edge, represented by significant White woman and Black woman effects in the first analysis, would disappear, or at least be reduced, by including the experience predictor.

\section{RESULTS}

\section{Differences in Market Experiences and Expectancies}

Black and White men and women differed in the types of changes they had attempted to make to improve their market position, but not in whether they had made any attempt. Approximately the same proportion of White men (43\%), Black men (34\%), and Black women (35\%) said they had tried to make some kind of change. Only White women differed, and then only from White men: Fewer White women $(26 \%)$ reported having made some attempt at improving 


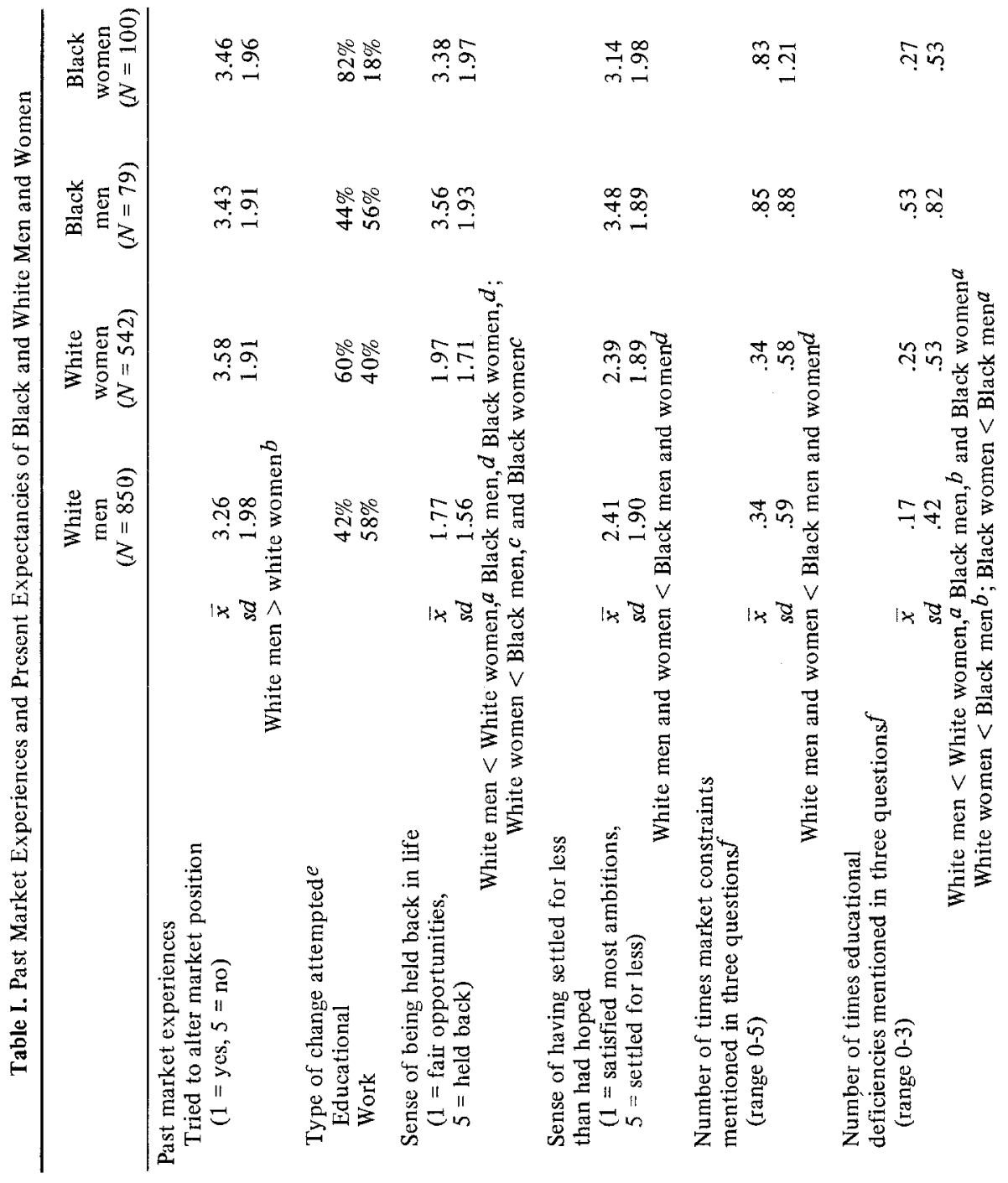




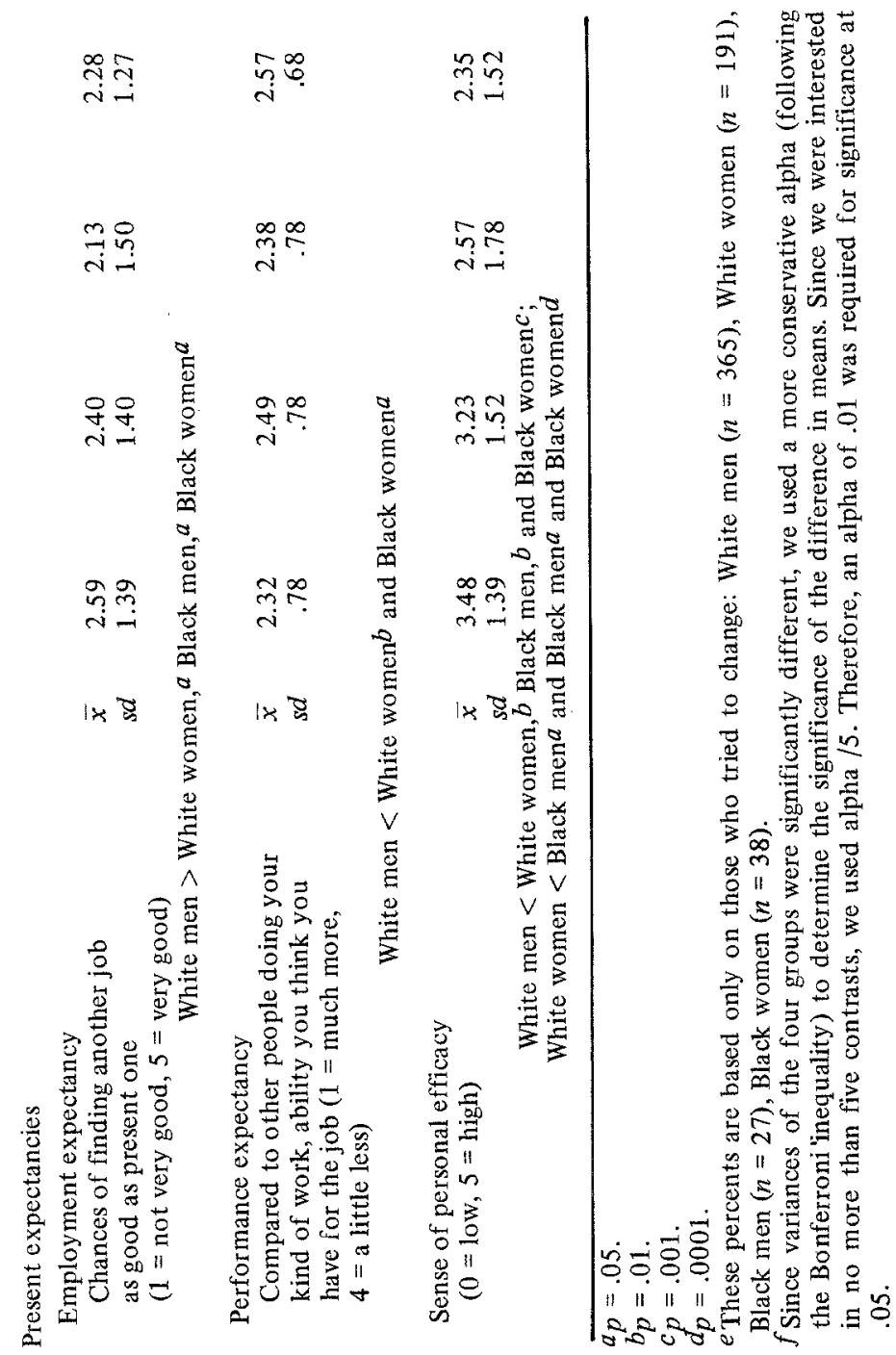


their market situation. The level of activity among those who had tried something was also comparable in the four groups. Approximately three-quarters of each group reported one change attempt, another fifth reported two attempts, and about $5 \%$ said they had tried three or more different things.

Men and women did differ, however, in the kinds of changes they had tried. More men (58\% White, 56\% Black) than women (40\% White, $18 \%$ Black) had tried some kind of work change or advanced job training. More women (60\% White, $82 \%$ Black) than men ( $42 \%$ White, $44 \%$ Black) had reported efforts to improve their educations. Work changes were thus more distinctively male, educational changes more distinctively female. Black women particularly stood out, even compared to White women, in the predominance of educational over work changes. (See Table I for comparisons of the means for the four groups.)

Negative experiences in trying to make these changes, as well as a sense of restriction (feeling held back and having settled in life), were expected to be more frequent among both groups of women and Black men than among White men. Table I shows main effects of race as well as the predicted White male edge relative to all groups. Whites more often felt they had fair opportunities to make something of their lives, had satisfied most of their ambitions, and less often attributed market difficulties to constraints in the market itself. Blacks more often felt they had been held back, had had to settle for less than they had hoped, and specifically talked about market constraints as a source of difficulty. In some respects White men stood out not only from Blacks but also from White women. White men less often felt held back and less often held their own educational deficiencies responsible for difficulties they had experienced. So, although White women felt less restricted than blacks, they did feel more limited than White men, particularly by their educational credentials.

White men also held an "expectancy advantage" over the other three groups (see Table I). They expressed higher employment expectancies, felt more optimistic about their performance abilities for the jobs they were holding, and scored higher in the sensê of personal efficacy. If anything, these results underestimate the actual White male advantage, since the employment and performance assessments were tied to the jobs these groups currently held. Both groups of women thus held lower expectancies about jobs that already pay less than the jobs held by White men. Black men likewise expressed lower employment expectancies (although not lower performance expectancies) for lower paying jobs. If salary and quality of jobs currently held by the four groups had been equated, the expectancy edge of White men would be even more pronounced.

\section{Investment Strategies and the Expectancies of Women}

We have just seen that women differed very little from men in whether they had previously tried to do something to improve their market value. Past 
discrimination seems not to have convinced women that it is unwise to invest in their human capital, since approximately the same proportion of women and men (White women slightly less) reported having tried something. The number of investments or improvement efforts women had tried was also comparable to that of men. Women did differ, however, in what they had tried. More men had invested in job training and job changes to improve their situations. More women, especially Black women, had invested disproportionately in additional schooling.

What were the "effects" of past investment efforts? This question assumes a temporal relationship between market experiences and expectancies that is supported by the way the questions were worded to respondents. The experience questions were all cast in the past: Was there ever a time when you tried to change your situation? Have you ever felt held back in life, etc.? The expectancy questions were all cast in the present, as in the personal efficacy and performance expectancies, or in future, as in the measure of employment expectancies.

The relationship between experiences and expectancies was examined first by running separate correlation matrices for the four groups of workers (see Table II). Investment in job-related changes, while rarer for women, was correlated significantly for both Black and White women with positive accounts of past experiences; the sense of being held back by family obligations, but not by market constraints or their educational credentials; confidence about their job performance abilities; and sense of personal efficacy. This contrasted with both groups of men. Job-related investments were largely discouraging for Black men and irrelevant to the expectancies and experience evaluations of White men.

The results for women show that those who had tried to improve their market situation by changing jobs or acquiring training on the job less often felt

Table II. Correlations Between Trying a Job Change and Other Labor Market Experiences: Expectancies for Black and White Men and Women

\begin{tabular}{lcccc}
\hline & $\begin{array}{c}\text { White } \\
\text { men } \\
(N=850)\end{array}$ & $\begin{array}{c}\text { Black } \\
\text { men } \\
(N=79)\end{array}$ & $\begin{array}{c}\text { White } \\
\text { women } \\
(N=542)\end{array}$ & $\begin{array}{c}\text { Black } \\
\text { women } \\
(N=100)\end{array}$ \\
\hline Years of schooling & -.05 & .02 & .07 & $.26 b$ \\
Held back in life & -.07 & $.35 b$ & $-.16 b$ & -.03 \\
Held back by educational credentials & -.01 & $.23 a$ & $-.23 c$ & $-.26 b$ \\
Held back by market constraints & -.07 & .03 & -.06 & -.15 \\
Held back by finances & $.13 b$ & $.29 a$ & .04 & .04 \\
Held back by family obligations & .07 & -.07 & $.22 c$ & $.46 c$ \\
High employment expectancy & -.01 & -.13 & $.09 a$ & $.30 b$ \\
High job performance expectancy & .03 & .01 & $.25 c$ & $.20 a$ \\
High personal efficacy & .05 & $-.22 a$ & $.19 b$ & $.27 b$ \\
\hline
\end{tabular}

$a_{p}=.05$.

$b_{p}=.01$.

$c_{p}=.001$. 


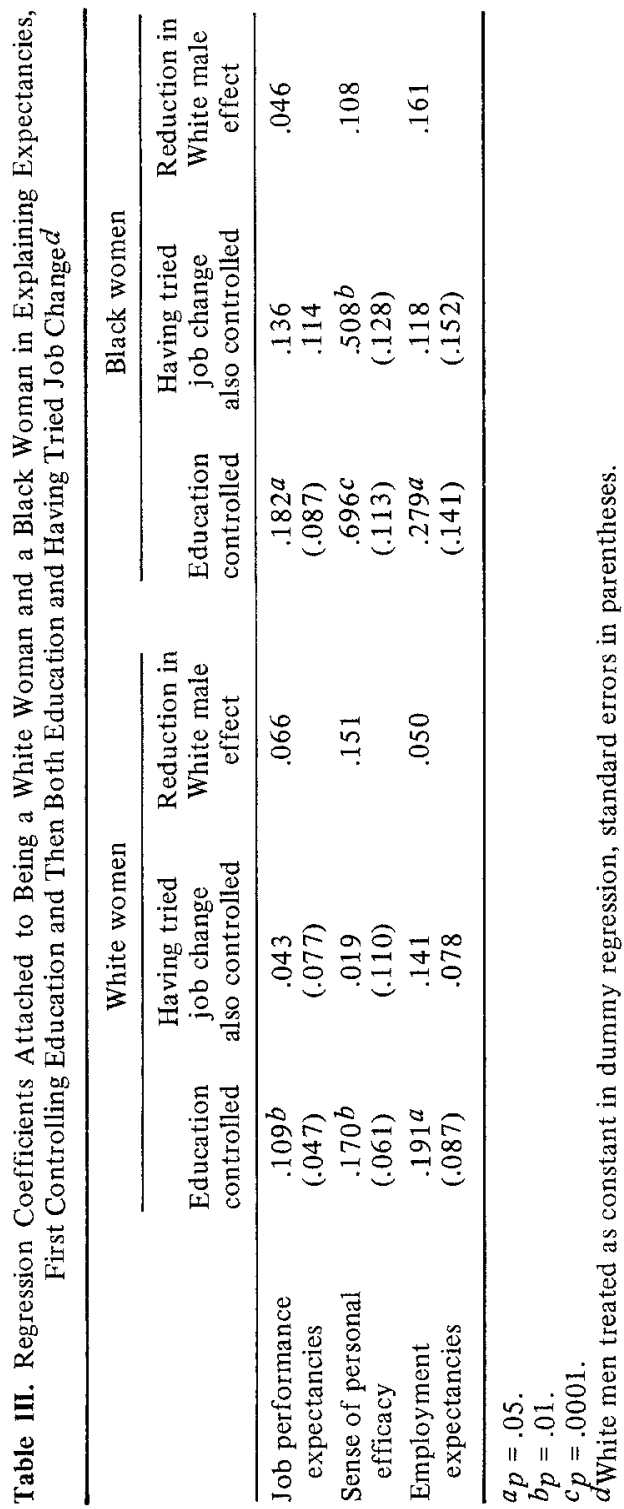


restricted by their educational qualifications. For Black women this is understandable, since Black women who had invested in job strategies were better educated than other Black women. But years of schooling did not account for which White women had tried to make job-related changes. These women may have learned from activity in the market that educational qualifications may not stand in their way. Women who do not have experience in trying to change jobs or move into better jobs may exaggerate the importance of educational credentials.

Women who had tried job changes also expressed higher expectancies. They held higher performance expectancies and also felt more generally efficacious. Their expectancies of being able to find other jobs at least as good as their present ones were also higher.

These results suggest that part of the White male edge in expectancies might stem from differences in the investment strategies that White men and the two groups of women had tried. The effect of this experience factor was tested through two dummy regressions, one in which the job investment predictor was included and one in which it was not. We expected that the significant White woman and Black woman effects in expectancies would disappear when the job investment predictor was included. This should happen because more White men had tried job changes, White men held higher expectancies, and job investment strategies and expectancies were positively related for both groups of women.

Table III shows that White men showed an advantage in expectancies, even with years of schooling controlled. (Differences presented in Table I were not controlled for education.) More important, these significant effects of being a Black woman or a White woman were no longer significant when adjustments were made for whether respondents had tried to make job changes. With only one exception (Black women's sense of personal efficacy), the dummy variable coefficients were not statistically significant when job investment and education were controlled. Black and White women did not express lower expectancies than White men when their investment strategies were equated.

\section{DISCUSSION}

The results support the general point that labor market socialization is an important area of research. Although women had invested in trying to improve their market situations just as often as White men, women had experienced more difficulties in the efforts they had made. In addition, the results demonstrate that workers' expectancies are sensitive to sex and that women's employment expectancies, performance expectancies, and sense of personal efficacy are related to the labor market experiences they had had as adults. The results further illustrate dramatically that the impact of experience on expectancies varies greatly 
for White men and Black men, as well as for both groups of women compared to either group of men. Generalizations about labor market experiences should be drawn very cautiously unless (as is rarely done) all four groups of workers are studied.

The particular investment strategies the women in our sample reported also suggest important issues for educators and counselors who work with women. Both groups of women, and especially Black women, more often reported efforts to improve their educational qualifications than attempts to alter their market positions through changing jobs, requesting promotions, or acquiring job training. While these results need to be replicated and further investigated in longitudinal studies, they raise the question whether this imbalanced investment in education is a reasonable strategy for women. This needs to be examined in two ways: (1) Is it reasonable for economic returns? (2) Is it reasonable for psychological benefits, even though they are not immediately, or perhaps ever, translated into economic returns?

Counselors who work with women who are returning to the labor market or with young women who are trying to plan their economic futures should be able to offer information about probable returns of various educational and jobrelated investment strategies. Unfortunately, most research, guided by human capital theory, has assumed that different types of work, educational, and training investments should have the same wage consequences and need not be distinguished. In addition, only a few studies have included minority as well as male and female workers in the same analysis. The few studies that have investigated whether returns to schooling and to job experience differ for different groups of workers are far from conclusive. Some show different returns for White men and for other groups of workers. Others do not. Thus, it is premature to use prior research to decide whether Black and White women's disproportionate effort at improving their education is functional for their market success. If most women end up in female jobs (either because they prefer them or settle for them), and if employers in such jobs stress middle level educational skills as Oppenheimer (1970) suggests they do, educational investment may be the only realistic path for large numbers of women workers to improve their earnings. If male jobs become increasingly available to women, the investment strategies of the women we studied may not be as advisable. Our results should provoke questions about what to advise women, especially since presently available evidence is far from clear that educational investments provide the best returns. These questions take on special significance, since information about educational programs and opportunities to gain training in formal educational settings presently exceeds information about jobs and training opportunities in job settings. Counselors may abet the "return to school" phenomenon not because they even think about whether that is the best strategy, but because they simply know more about educational than employment possibilities. 
The second set of questions that might be raised from these results concern the psychic returns of educational and job-related investments. Women who tried to make work changes were more self-confident about their job abilities, were more optimistic about finding another job at least as good as their present one, and felt better able to control what happened in their lives. Since most people reported only one previous attempt to improve their situations, it would be expected that job and educational investments acted as alternatives. Thus, women who tried educational changes understandably exhibited less confidence, lower employment expectancies, and felt less efficacious generally in life. Obviously, job and educational investments need not be alternatives, and their effects are surely not as opposite as our results seem to imply. Still, job, rather than educational, investments had the more positive expectancy implications. This is important even if expectancies in no way subsequently influence labor market behavior.

\section{REFERENCES}

Barnett, R. C. Sex differences and age trends in occupational preference and occupational prestige. Journal of Counseling Psychology, 1975, 22, 35-38.

Crowley, J., Levitin, T., \& Quinn, R. The seven deadly half-truths about women. Psychology Today, March 1973, pp. 94-96.

Feldman, S. D. Escape from the doll's house: Women in graduate and professional school education (A report prepared for the Carnegie Commission on Higher Education). New York: McGraw-Hill, 1974.

Gurin, P. The role of worker expectancies in the study of employment discrimination. In P. A. Wallace \& A. M. LaMond (Eds.), Women, minorities and employment discrimination. Lexington, Mass.: Lexington Books, 1977.

Gurin, P., \& Morrison, B. M. Education, labor market experiences, and current expectancies of black and white men and women. Ann Arbor: Institute for Social Research, 1976.

Gutek, B. A., \& Nieva, B. F. Career choice processes in women. Paper presented at the meeting of the American Psychological Association, Toronto, August 1978.

Hamilton, M. T. Sex and income inequality among the employed. Annals of American Academy of Political and Social Sciences, 1973, 409, 42-52.

Laws, J. L. Psychological dimensions of labor force participation of women. In P. A. Wallace (Ed.), Equal employment opportunity and the AT\&T case. Cambridge, Mass. : M.I.T. Press, 1976.

Looft, W. R. Vocational aspirations of second-grade girls. Psychological Reports, 1971, 28, 241-242. (a)

Looft, W. R. Sex differences in the expression of vocational aspirations by elementary school children. Developmental Psychology, 1971, 5, 366. (b)

Oaxaca, R. Male-female wage differentials in urban labor markets. International Economic Review, 1973, 14(3), 693-709.

Oppenheimer, V. K. The female labor force in the United States: Demographic and economic factors governing its growth and changing composition. Population Monograph Series, No. 5. Berkeley: University of California, 1970.

Shepard, W. O., \& Hess, D. T. Attitudes in four age groups toward sex role division in adult occupations and activities. Journal of Vocational Behavior, 1975, 6, 27-39.

Siegel, C. L. F. Sex differences in the occupational choices of second graders. Journal of Vocational Behavior, 1973, 3, 15-19. 
Suter, L. E., \& Miller, H. P. Income differences between men and career women. American Journal of Sociology, 1973, 78(4), 962-975.

Tangri, S. Determinants of occupational role innovation among college women. Journal of Social Issues, 1972, 28, 117-129. 